\title{
策 \\ RACIONALIZAÇÃO DA ASTREINTE À OBTENÇÃO DA TUTELA ESPECÍFICA SOB A PERSPECTIVA DO DIREITO FUNDAMENTAL À SATISFAÇÃO E DA ATIPICIDADE EXECUTIVA
}

\author{
RATIONALIZATION OF THE ASTREINTE TO OBTAIN SPECIFIC TUTELAGE \\ UNDER THE PERSPECTIVE OF THE FUNDAMENTAL RIGHT TO SATISFACTION \\ AND THE ATYPICAL EXECUTION
}

\section{RACIONALIZACIÓN DEL ASTREINTE PARA OBTENER TUTELAS ESPECÍFICAS BAJO LA PERSPECTIVA DEL DERECHO FUNDAMENTAL A LA SATISFACCIÓN Y LA ATIPICIDAD EJECUTIVA}

Vitor Henrique Melo de Albuquerque ${ }^{1}$

\begin{abstract}
Resumo: O presente trabalho se insere no novo modelo de flexibilização processual que busca atribuir à função jurisdicional poderes suficientes para a ssegurar a efetividade da ativida de satisfativa. Considerando a multa coercitiva como instrumento para atingir o direito fundamentalà efetividade da tutela jurisdicional a dequada, a análise intenta a lertar a os operadores do direito sobre a necessida de da racionalização de sua a plicabilida de no ca so concreto, tendo em vista a atipicida de executiva e a busca pela tut ela específica. Para tanto, utilizou-se um especia liza do acervo doutrinário sob o qualfoi possível concluir, a tra vés dos conceitos e linhas teóricas extraídos, que a multa em comento detém vários aspectos que merecem ser melhor ajustados ca suisticamente.
\end{abstract}

Palavra-chave: Efetividade; Multa coercitiva; Tutela específica; Atipicidade.

\begin{abstract}
The present work is inserted on a new model of procedural flexibility that seeks to attribute to the jurisdictional functions allowed to guarantee the effectiveness of the satisfactory activity. Considering the coercive fine as an instrument to a chieve the funda mental right to the effectiveness of adequate judicial tutelage, an analysis intended to a lert legal operators about the need to rationalize its applicability in the specific case, with a view to executive atypicality and a search for specific tutelage. To do so, use a collection of qualified clinical trials or which it was possible to conclude, through extra theoreticalconcepts and lines, that, as many show some aspects that deserve to be better case by case.
\end{abstract}

Keywords: Effectiveness; Coercive fine; Specific tutelage; Atypicality.

Resumen: El presente trabajo es parte del nuevo modelo de flexibilidad procesalque busca dara la función jurisdiccional poderes suficientes para garantizar la efectividad de una actividad satisfactoria. Considerando la multa coercitiva como un instrumento para lograr el derecho fundamental a la efectividad de una protección judicial a decuada, el análisis pretende a lertar a los operadores del derecho sobre la necesidad de racionalizar su a plicabilidad en el ca so específico, en vista de la atipicidad ejecutiva y la búsqueda de tutela específica. Para ello, se utilizó una colección doctrinal especializada en virtud de la cual fue posible concluir, a tra vés de los conceptos y líneas teórica extraídas, que la multa objeto de comentario tiene varios aspectos que merecen ajustarse mejor caso porcaso.

Palabras clave: Efectividad; Multa coercitiva; Tutela específica; Atipicida d.

\footnotetext{
${ }^{1}$ Mestrando em Direito Público na Universidade Federal de Alagoas, na linha de Fundamentos constitucionais do direito privado e do direito processual. E-mail: vitor.henrique0109@gmail.com
} 


\section{INTRODUÇÃO}

O estudo em torno da execução sempre guardou preocupações no que se refereà obtenção das obrigações que dependam de alguma conduta do responsável. É que por muito tempo o processo civil de origem liberal se preocupou, em grande justeza, com as liberdades dos indivíduos e os limites que o Estado poderia atingir na esfera jurídica de cada um. Consequentemente, as prestações que dependiam de ação costumavam se consumar em perdas e danos, exigindo-se a reparação em dinheiro.

No entanto, com a nova gama de direitos que foi sendo desenvolvida, com ênfase no caráter social e democrático dentro da conjuntura de guerras e de aprimoramento das constituições, foi-se compreendendo que a tutela jurisdicional adequada também consistia em objetivo a ser resguardado pelo processo, pois o instrumento deveria ser capaz de transformar a realidade para, finalmente, materializar o direito substancial. Nesse sentido, a tutela específica surge como resultado da valorização do exequente, colocando-lhe como detentor de verdadeiro direito fundamental à ef etividade da tutela adequada.

Apesar de o progresso ter se sucedido historicamente, o novo Código de Processo Civil brasileiro foi arrematador, pois ultimou a execução como atípica, flexibilizando ainda mais a aplicação das técnicas disponíveis e permitindo a criatividade jurisdicional, bem como alavancou terminantemente a efetividade da atividade satisfativa como uma das finalidades precípuas do devido processo legal.

Outrossim, a multa coercitiva, também conhecida por astreinte, constitui em antiga técnica executiva desenvolvida justamente no intuito de coagir um indivíduo a cumprir com determinada ordem, a fim de superar sua deliberada recalcitrância. Contudo, numa sistematização processual flexível, em valor da execução atípica e de realce ao direito fundamental à efetividade da tutela jurisdicional adequada, também a astreinte deve ser revista para que ocorra sua racionalização concreta.

Nesse desiderato, serão abordados inicialmente os contornos da tutela específica no $\mathrm{CPC} / 15$ e em seguida explorada a reafirmação da multa como instrumento do direito fundamental à efetividade da tutela satisfativa. Ao final, examinar-se-á de que modo a astreinte deve ser racionalizada sob a égide de uma execução atípica, fazendo-se necessário investigar os aspectos que lhe envolvam e que precisam ser amoldados diante de cada situação apresentada, a fim de atingir o melhor êxito possível e a execução possa, portanto, alcançar o fim que ela se propõe, que é de satisfazer o exequente sem agredir injustamente a ordem jurídica.

\section{CONTORNOS DA TUTELA ESPECÍFICA NO CPC/15}

É de notório conhecimento que a ordem jurídica instaurada no seio social tem a finalidade elementar de preceituar condutas comissivas ou omissivas dos indivíduos e das coletividades, no intuito de preservar a sociedade como um todo e promover aspectos que não seriam alcançados 
livremente. Nesse sentido, em termos extremamente simplórios, o processo ficará responsável pela instrumentalização hábil a efetivar, reconhecer ou constituir as situações jurídicas dispostas pelo direito substantivo.

Na categorização das obrigações correspondentes ao devedor perante à sistematização normativa, aquelas que dependem da própria postura do obrigado causam "maiores transtornos ao credor, quando se de fronta com inadimplemento" (VENOSA, 2017, p. 81). Isto é facilmente factível porque se o cumprimento depende, muitas vezes necessariamente, do atingimentode uma conduta individual, já que a relação tem por objeto prestação de ação, significa que apenas restam duas opções: ou o credor se contenta com algo que lhe satisfaça de forma equivalente, ou o processo deve dispor de técnicas suficientes para que se permita alcançar a execução específica. E é sobre esta segunda alternativa que os problemas se insurgem consideravelmente.

Em síntese, a disposição da tutela específica tem por objetivo oferecer exatamente o cumprimento obrigacional ignorado pelo devedor e contido no título executivo, satisfazendo-lhe concreta e igualmente o que seria obtido se o obrigado adimplisse voluntariamente. Conseguintemente, “distingue-se da noção de execução genérica ou substitutiva, que tem a finalidade de atingir uma obtenção em dinheiro do valor equivalente à obrigação devida, que seria satisfatoriamente substituída" (RODRIGUES, 2006, p. 115). Sobre esse ponto, entende-se que a perspectiva da tutela processual deve conformar as necessidades do direito material, de modo que as técnicas instrumentais atendam à missão constitucional de tutelar efetivamente os direitos. (MARINONI, 2019,p. 101)

Todavia, historicamente a visão da especificidade executiva não era bem vista. Na medida em que o indivíduo se fortaleceu como centro da normatização jurídica, a partir da modernização dos estados e do enfraquecimento das monarquias, a posição liberal e protetiva impedia que ele pudesse ser pessoalmente compelido a executar a prestação prometida ou assegurada ao credor. Era esse o princípio dominante do Código Napoleão, onde dispunha que o cumprimento obrigacional deveria recair somente sobre o patrimônio, impedindo que houvesse sofrimento executivo de ordem pessoal. (THEODORO JÚNIOR, 2002, p. 01)

Inclusive, vale destacar que a diretriz jurídica brasileira é fortemente influenciada pela clássica filosofia ocidental de John Locke e Thomas Hobbes. Quanto ao primeiro, sua ponderação sistematizada com base em três direitos inerentes ao homem - propriedade, liberdade e vida fundamenta, basicamente, as opções constitucionais do Estado. Por exemplo, com a exceção do art. $5^{\circ}$, XLVII, alínea a, da CF/88, a vida não pode ser atingida deliberadamente, restringindo-se à propriedade e à liberdade. Sobre esta, como dito acima, apenas no caso de dívida alimentícia pode ser afetada, além das penalizações criminais. Resta, portanto, para o terreno cível, a propriedade, indicando que, de forma geral, apenas o patrimônio pode ser afetado para o cumprimento obrigacional. Neste caso, é a imperatividade jurisdicional que irá compelir as pessoas - em sentido amplo - ao devido cumprimento dos seus deveres jurídicos. É aqui onde se 
destaca a influência de Hobbes, ao considerar que os homens, em sua natureza, vivem em estado de selvageria, onde somente o Leviatã seria capaz de cessar o caos.

Contudo, o sistema processual não poderia ficar à mercê da inadimplência das obrigações específicas, pois, ao contrário, deveria sempre buscar respostas diversificadas, a fim de corresponder ao máximo o que resta assegurado pelo direito material, proporcionando fielmente, por consequência, a situação que existiria se não houvesse descumprimento deliberado. Esse entender se deve, em grande magnitude, à defesa de Giuseppe Chiovenda, ainda no início do século XX, por um processo de execução que ofereça os instrumentos necessários para a tutela de todos os direitos, assegurando aos cidadãos a utilidade das decisões. Trata-se, portanto, da aclamada efetividade do processo, e é neste ponto que a tutela específica assume realce, pois deve guardar remédios e providências tendentes a garantir o resultado prático que seria atingido pelo adimplemento (GRINOVER, 2011, p.01).

Nesse exato sentido, conclui-se que o processo é valorado conforme a utilidade que ele é capaz de ofertar ao direito material, sendo diretamente proporcional ao grau de solução dos problemas (FONSECA E SILVA, 2019, p. 80). Justamente por esse entendimento que a natureza das medidas executivas deve estar pautada em consonância com a finalidade da execução (MEDINA, 2017, p. 288).

Com fundamento na máxima chiovendiana acima abordada - que o processo deve dar o exato bem que teria direito a quem tenha razão -, Fredie Didier Júnior (2004, p. 15) desde há muito já apontava que a execução civil deve dispor de técnicas para proporcionar ao jurisdicionado a coincidência entre o direito material e o resultado obtido no processo, revelandose na primazia da tutela específica. O referido autor já registrava, ainda, que as reformas processuais do fim do século passado e as iniciadas nos anos 2000 já estavam atribuindo muita importância a esse princípio executório.

A demora para as ousadas alterações processuais se deve ao caráter histórico-cultural do processo civil nas sociedades, pois "praticamente inexistente como técnica ou ciência autônoma, apresentava-se como mero apêndice do direito material" (THEODORO JÚNIOR, 2002, p. 02), em nada acrescentava no quesito técnicas ou medidas criativas disponíveis para fortificar a ef etividade dos preceitos substanciais.

Com ef eito, por muito tempo a recalcitrância do indivíduo responsável a cumprir com suas obrigações devidas foi encarada como limite intransponível, isto porque a intangibilidade da vontade humana era verdadeiro dogma conquistado e de valor extremamente relevante a ser preservado, razão pela qual a tutela relativa às prestações de fazer ou não fazer não encontraram respaldo na sistematização executória. (GRINOVER, 2011, p. 02)

No entanto, conforme se apontou, o caráter da efetividade executiva trazida por Chiovenda indica que o sistema processual deve oferecer situação semelhante ao que ocorreria em cumprimento normal e tempestivo da obrigação, precisamente porque se a situação dada de 
direito material é valorizada pela sociedade e posta legalmente, deve haver, consequentemente, sistemática executória bastante para proteger essa realidade (NETTO, 2000, p. 03 e 05), o que vem implicar, inclusive, na plasticidade dos provimentos que contribuam para o asseguramento da satisfação (MARINONI, 2019, p. 145).

Pois bem. Foi com a impactante reforma legislativa promovida pela Lei n. 8.952/94 que alterações profundas foram feitas no Código de Processo Civil brasileiro de 1973 no art. 461. Até esse momento, o dogma da intangibilidade era quase que absolutamente respeitado e sustentava as decisões da época. Após essa sensível mudança, a transformação da mentalidade jurídica foi permitindo asseverar que a resistência do devedor não pode mais constituir entrave à satisfação, sendo até mesmo possível afirmar que se a "ausência de coerção implicar em perda do tônus da efetividade da atividade executiva, por menor que possa ser essa perda, então não se justifica deixar de aplicá-la" (OLIVEIRA NETO, 2019, p. 235), ideia que apenas reforça a valorização da efetividade das obrigações específicas.

O Código Civil de 2002 buscou assinalar a possibilidade de o credor exigir a obrigação de fazer ou não fazer do devedor através de terceiro, mas ainda assimé bastante tímido, tendo em vista o disposto nos art. 247, 248 e 250, os quais dispõem categoricamente sobre a extinção da obrigação resolvendo-se em perdas e danos.

O novo Código de Processo Civil, por sua vez, foi arrebatador no art. 499, ao preceituar que as obrigações de fazer, não fazer ou entregar coisa somente serão convertidas em perdas e danos se o autor assim requerer, ou se impossível a tutela específica ou a obtenção de tutela pelo resultado prático equivalente. Esta colocação é especialmente importante para ultimar a argumentação acerca da tutela específica na legislação processual e os dogmas anteriormente estabelecidos.

Esta regra tem a finalidade clara de estabelecer uma hierarquia de preferência no oferecimento da tutela satisfativa, fixando a especificidade num patamar superior ao mero ressarcimento, de modo que a obrigação específica não pode ser transformada pura e simplesmente em pagamento em dinheiro. Inclusive, como será ainda melhor explorado, essa imposição legislativa decorre da própria natureza dos direitos e do direito fundamental à efetividade da tutela jurisdicional. (MARINONI, 2020, p. 04)

A opção adotada pelo CPC/15 é lúcida também no art. 536, o qual aponta que o juiz poderá, para efetivação da tutela específica, determinar as medidas necessárias para a satisfação do exequente, a exemplo e em reforço ao que já dispunha o CPC/73.

Percebe-se, então, que o novo código apenas bem refletiu o que já era tendência doutrinária e legislativa, reforçando e robustecendo a primazia da tutela específica. Não precisa muito esforço para notar que a tutela das obrigações específicas meramente convertidas em pecúnia não se adapta a inúmeras situações, com ênfase àquelas de cunho não patrimonial, pois se liga frequentemente a direitos fundamentais ou da comunidade que simplesmente não eram 
previstos ou assegurados outrora. (GRINOVER, 2011,p. 02)

Por essa razão, passou-se a focar em metas que iriam bem além da composição das lides, do provimento judicial e de procedimentos tipificados para a execução de pagar quantia. Isto é, a visão judicial se vinculou à preocupação justa com a efetividade executória, na perseguição de resultados que correspondessem à melhor e mais justa resolução. Assim, esse novo caminho a ser trilhado exigia o desenvolvimento de técnicas que permitissem opções convenientes para o caso concreto apresentado, propiciando ao direito material conferido a mais plena tutela, (THEODORO JÚNIOR, 2002, p. 02), considerando, principalmente, que as novas situações de direito substancial correlatas ao dever de proteção do Estado não permitem que se aceite técnica processual inadequada (MARINONI, 2019, p. 112).

\section{REAFIRMAÇÃO DA MULTA COERCITIVA COMO INSTRUMENTO DO DIREITO FUNDAMENTAL À EFETIVIDADE DA TUTELA SATISFATIVA}

Como visto, a tutela específica encontrou limites seculares que a impediam, mas que gradativamente foram cedendo espaço para a nova gama de direitos e a necessidade de oferta da efetividade aos jurisdicionados.

Nessa linha de pensamento, não se perde de vista que a realização específica do direito material encontra limites no processo, revelando-se, na verdade, como de sua própria característica, pois a ordem pública processual guarda consigo a essência garantista e limitadora da vontade dos envolvidos, ainda que haja a moderna tendência - adequada, necessária e legítima - de sua flexibilização. Por outro lado, a dimensão social do processo encontra guarida na confiança depositada pelo jurisdicionado para a resolução de seus imbróglios. Mais que isso, o cidadão espera ver seu direito reconhecido efetivamente satisfeito, ou seja, que transforme a realidade para colocar a "declaração formal de seu direito em atividade dinâmica e realizadora concreta no mundo dos fatos." (GAIOJÚNIOR, 2019,p. 03)

Não por outra razão o novo CPC dispõe, no art. $4^{\circ}$, que "as partes têm o direito de obter em prazo razoável a solução integral do mérito, incluída a atividade satisfativa." Ou seja, o legislador foi cirúrgico em reforçar, ainda que não seja necessário, a atividade satisfativa como direito a ser protegido entre as normas fundamentais do processo civil, pois "dado o fato de haver uma decisão judicial, deve ser o direito do interessado à obtenção da realização efetiva do julgado". (NOGUEIRA, 2011, p.07 e 08)

Luiz Guilherme Marinoni (2020, p. 14) elucida com maestria que o direito ao ressarcimento na forma específica está contido no direito à ef etivae adequada tutela jurisdicional, disposto na $\mathrm{CF} / 88$, no art. $5^{\circ}, \mathrm{XXXV} . \mathrm{O}$ autor disseca que o direito à efetividade satisfativa é direito fundamental que encontra raiz na própria dignidade da pessoa humana, a qual é fundamento do Estado Democrático de Direito. Consequentemente, o desapreço pela tutela específica desconsideraria completamente não apenas o direito material assegurado 
casuisticamente, mas também um direito fundamental erigido pelo constituinte. Prossegue o professor paranaense apontando que de nada adianta assinalarum direitocomo fundamental e não extrair daí o significadonecessário e correspondente. Nessalogicidade, o direito fundamental tem aplicabilidade imediata, estando os órgãos públicos vinculados ao seu conteúdo, o que, no tema em tela, impõe ao magistrado a interpretação e a aplicação necessária à busca da técnica processual adequada para conferir efetividade à execução.

Inclusive, a própria vedação feita pelo ordenamento à autotutela conduz à ideia da obrigatoriedade de uma tutela jurisdicional efetiva enquanto direito fundamental. Isto porque não basta o acertamento do direito se ainda restam pendentes atos práticos a sua concretização fática. Logo, o acesso à justiça deve certific ar ao jurisdicionado o inexorável arcabouço à ef etivação do que lhe é devido. (CUNHA; SCALABRIN, 2017, p. 02)

Sob essa ótica, entende-se que o devido processo abarca a oferta de tudo aquilo e exatamente aquilo que seja possível a quem detenha um direito, pensando-se na correlação entre o direito fundamental à adequada tutela jurisdicional e às técnicas hábeis e suficientes para dar resposta satisfatória ao direito material. (ATAÍDE JÚNIOR, 2008, p. 25)

Justamente por essa congruência processual que o desenvolvimento de técnicas executivas tendentes a assegurar a tutela específica não ofende meramente os clássicos direitos limitadores do executado, pois, ao contrário, são estes apenas flexibilizados diante do caso concreto. Melhor dizendo, a imposição de artifícios imperativos para que se alcance o resultado que deveria ter sido alcançado pelo cumprimento voluntário do obrigado em nada arranha a dignidade da pessoa humana de quem se vê compelido a cumprir com a ordem proferida. (RODRIGUES, 2006, p. 86)

A construção normativa de que a efetividade executiva consiste em norma fundamental não é isenta de ressalvas, isto porque essa aferição é comumente feita sem definições precisas de conteúdo, sendo capaz de conformar toda a estrutura normativa através do indesejado protagonismo judicial (DURO, 2018, p. 100). Contudo, insta gizar que o aumento do poder judicial não implica, necessariamente, em práticas autoritárias. Na verdade, se bem incrementado, tem o condão de servir aos propósitos da própria democracia do sistema jurídico (RAMOS, 2019. p. 35).

Neste ínterim, as preocupações referentes à funcionabilidade das técnicas executivas disponíveis não autorizam a exclusão de possibilidade do uso de tais mecanismos, sendo certo o dever de observância quanto aos limites de aplicação (OLIVEIRA NETO, 2019, p. 246). Ou seja, há de ser feita uma verdadeira adequação entre os sujeitos de direito figurantes na relação constituída, o que não significa agressões injustificadas, ilegais ou ilegítimas à esfera jurídica do atingido.

Nessa seara, o novo modelo processual valorativo acerca da efetividade levou ao aprimoramento de técnicas processuais capazes de atingir a obrigação específica. A mais clássica 
delas, sem sombra de dúvidas, é a multa coercitiva, a astreinte, concebida justamente "para induzir o devedor a cumprir espontaneamente as obrigações que lhe incumbem, princip almente as de natureza infungível" (GRINOVER, 2011, p. 03). Sinteticamente, a multa aqui abordada não tem a finalidade de substituir a obrigação ou incidir em caráter punitivo, mas tão somente em pressionar o executado para determinada satisfação (MEDINA, 2017, p. 594 e 595).

A palavra astreinte é oriunda do Direito francês, que denota uma sanção pecuniária a ser cumprida. $\mathrm{O}$ vocábulo vem do latim stringere, formado usualmente com o prefixo $a d$, que significa "para apertar" (GEBRIM, 1996, p. 69), justamente indicando o teor de estreitar, pressionar ou espremer a uma conduta querida. Conclui-se, então, pela análise etimológica do termo, que "a astreinte é uma ordem pecuniária pronunciada pelo juiz e destinada a superar a resistência de um devedor recalcitrante." (CHABAS, 201 1, p. 01, tradução nossa) ${ }^{2}$

Guilherme Rizzo Amaral (2015, p. 1404), referência brasileira no estudo, aponta que, a despeito de outros dispositivos do CPC/15, o art. 537:

(...) trata da disciplina da multa, seja ela periódica ou fixa, também conhecida como astreinte, dada sua origem no Direito Francês. Trata-se de técnica de tutela coercitiva e acessória, que visa a pressionar o réu para que este cumpra mandamento judicial, sendo a pressão exercida atra vés de ameaça ao seu patrimônio, consubstanciada em multa, fixa ou periódica, a incidir em caso de descumprimento.

Conclui-se, portanto, que a multa em comento representa medida pecuniária que tem por finalidade compelir alguém a cumprir com determinado comando, ou seja, para constrangê-lo ao efetivo cumprimento da ordem. Em tal logicidade, a aplicação da astreinte é corolário da inevitabilidade e da inafastabilidade da jurisdição.

Ora, se a efetividade da tutela jurisdicional satisfativa consiste em direito fundamental, ao tempo em que o Estado-juiz deve dispor de meio suficiente para tanto, nada mais congruente que a função jurisdicional alveje sua imperatividade através da medida coercitiva, simultaneamente ao dever de guardar o mínimo de resultado prático e efetivo ao que o direito material dispôs. Assim, a multa consistirá em instrumento de reforço à inevitabilidade e à inafastabilidade jurisdicional.

Ainda nesse ínterim, admitir e reconhecer a coercibilidade inerente à natureza da astreinte é determinante para sua aplicação futura. Nos dizeres de Rafael Caselli Pereira (2018, p. 35 e 36), "a natureza jurídica da astreinte consiste em seu caráter coercitivo, intimidatório, acessório e patrimonial". Em seguida, o referido autor também aponta que a multa está "inarredavelmente ligada à mora do devedor, visando a atuar no sentido psicológico de que o obrigado cumpra espontaneamente o preceito, constituindo medida coercitiva e inibitória".

Por esse motivo, no momento de fixação da multa, a finalidade não gira em torno de

\footnotetext{
${ }^{2}$ No original: "l'astreinte est une condamnation pécuniaire prononcée par le juge et destinée à vaincre la résistance d'un débiteur récalcitran"
} 
eventual ressarcimento do prejuízo com o inadimplemento, ou qualquer outra forma compensatória pela não obtenção da tutela específica. Na verdade, o objetivo é tão somente de superar a postura de resistência do devedor, constrangendo-lhe psicologicamente a uma conduta. (MARZAGÃO, 2013, p. 114)

Categorizada a astreinte enquanto medida coercitiva desfecha-se, então, que ela não se realiza diretamente para o cumprimento de uma finalidade. Na verdade, ela é genuínoinstrumento que força o destinatário a agir como teria agido espontaneamente, suportando as consequências de sua eventual inércia e recalcitrância (OLIVEIRA NETO, 2019, p. 237).

A fim de consumar a natureza jurídica da astreinte, Bruno Garcia Redondo (2013, p. 02) apresenta a noção intrínseca da coerção e a respectiva ausência de caráter indenizatório da astreinte. De início, a fixação da multa independe do valor da obrigação principal como parâmetro. Segundo que é possível cumular a astreinte com indenização por perdas e danos. Ademais, o fundamento da multa é a mora do obrigado, não o inadimplemento integral. Por fim, a astreinte ainda pode ser estabelecida antes da ocorrência de qualquer dano ou direito violado, não guardando relação, portanto, com eventual indenização.

As características acima apresentadas são extraídas da própria legislação, vide o art. 500 do CPC/15, por exemplo, ao dispor que a indenização por perdas e danos dar-se-á sem prejuízo da multa periódica. Ademais, o art. 537 do mesmo diploma estabelece que a multa deverá ser suficiente e compatível com a obrigação, não estabelecendo qualquer limitação de valor. Assim, resta evidente a ausência de caráter reparatório na multa em comento, visto que sua função é superar a obstinação do devedor a determinado cumprimento obrigacional, incidindo a partir da recalcitrância. (PEREIRA, 2018, p. 82)

A conclusão do raciocínio aqui levantado é relativamente simples, pois se a efetividade da tutela jurisdicional satisfativa consiste em direito fundamental e a multa coercitiva consiste em importante técnica executiva, significa, consequentemente, que a aplicação adequada da astreinte tem o condão de materializar o próprio direito fundamental do acesso à justiça, além de transformar a realidade do direito substancial já reconhecido. É justamente sobre essa adequação que agora se debruça, considerando o contexto da atipicidade executiva do sistema processual brasileiro.

\section{RACIONALIZAÇÃO DA ASTREINTE NO CONTEXTO DA ATIPICIDADE EXECUTIVA}

Abordada a natureza jurídica da astreinte, a conceituação da execução da tutela específica e o direito fundamental à efetividade da respectiva tutela jurisdicional satisfativa adequada, chegou-se à conclusão de que a multa coercitiva é instrumento dos mais relevantes para concretizar o processo de resultados, aquele em que o jurisdicionado se satisfaz com a transformação do direito substancial em realidade. 
Nesta exata medida, em busca da efetividade da ordem emanada sobre uma prestação de ação, os arts. 536 e 538 do CPC viabilizam expressamente o uso da multa, permitindo ao juiz a decretação de medidas que sejam necessárias para a efetivação do direito, conforme as peculiaridades do caso concreto. (MARINONI, 2020, p. 11)

Urge destacar que atualmente se vive um momento de busca por técnicas e mecanismos cada vez mais capazes de adaptar o direito à realidade fática dos jurisdicionados, no claro intuito - justo e nobre - de acabar com a injustiça de não se ter satisfeito um direito já reconhecido, o que provoca desconfiança, descrédito e sentimento de impunidade. (GAIO JÚNIOR, 2019, p. 08)

É que o processo contemporâneo abarca bens jurídicos até mesmo inima gináveis há algumas décadas, nascidos de um novo modelo constitucional e de interesses sociais vanguardistas, para cuja proteção o processo é crucial, haja vista ser meio operante e instrumental para sua materialização. Nessa linha, é através de técnicas executivas adequadas, com ênfase nas obrigações específicas, que os valores assegurados substancialmente são efetivados, valores estes que se revelam como referencial expressivo da tendência do sistema jurídico, tais quais, por exemplo, os direitos a serem assegurados pela Lei da Ação Civil Pública e pelo Código de Defesa do Consumidor. (NETTO, 2000, p. 08)

Sob essa perspectiva, diante da teoria dos direitos fundamentais, não cabe mais pensar nas fechadas formas executivas típicas, modelo clássico do processo civil liberal que imperou por muito tempo, cuja intenção era limitar o Estado-juiz para garantir a liberdade do cidadão. (MARINONI, 2020, p. 14)

A valer, no percalço de superar as barreiras impostas pelo legislador e permitir a criatividade casuísticajurisdicional, no desígnio de satisfazer o exequente, a atipicidade executiva encontrou respaldo no sistema jurídico brasileiro há alguns anos e se consolidou com o novo Código. O raciocínio impõe o desfecho de que se o direito material não está sendo reali zado, ao tempo em que o direito fundamental à efetividade da tutela satisfativa está sendo violado é dever do Estado impedir que tais afrontas se perpetuem. Destarte, a atribuição de poder criativo ao judiciário para a fixação das medidas executivas atípicas mais adequadas ao caso concreto tão somente deslinda a clara finalidade legislativa em tornar a execução eficaz.

Esse desígnio é extraído de qualquer sistema que pretenda atender às exigências apresentadas pelo direito material, adequando a proteção dos novos direitos ou estes em novas abordagens axiológicas, isto é, o modelo processual deve prever mecanismos hábeis de efetivar a satisfação das prestações no menor espaço de tempo e com o mínimo necessário de atividade. (OLIVEIRA NETO, 2019, p. 223).

Tal preocupação, como se disse, não é recente, mas ganhou exponencial força com a vigência da nova legislação processual, vide os art. $4^{\circ}, 6^{\circ}, 139$, IV, 297, 536 e 771, todos do CPC/15, de modo que "o desenvolvimento da execução ao longo dos últimos anos no Brasil demonstra uma tendência, confirmada no atual Código, no 
sentido de generalizar a atipicidade" (MINAMI, 2019, p. 09)

Precisamente, quanto maior a credibilidade no sistema normativo e a necessidade de novos contornos da efetividade, maior também a liberdade linguística que torne apta a complementação do texto legal. Sobre esse ponto, as cláusulas gerais exercem importantes funções que estão atreladas ao que aqui se discute, pois permitem a criação de normas por parte do juiz, asseguram a flexibilidade do sistema a responder novos fatos e novas demandas, bem como contribuem para a integração do ordenamento. (BORGES, 2019, p. 85)

No que interessa agora, Eduardo Talamini (2018, p. 03) salienta que a lei confere amplos podres jurisdicionais para a perseguição da tutela específica ou, ao menos, do resultado correspondente, evidenciando que a larga concessão desses poderes almeja obter a própria atuação do obrigado a cumprir com o que lhe cabe e foi determinado, seja pelo título executivo ou por alguma diversa ordem judicial.

A astreinte, como se viu, consiste em técnica executiva típica e, portanto, tem previsão expressa no CPC $/ 15$, conforme os art. $536, \S 1^{\circ}, 806, \S 1^{\circ} \mathrm{e} 814$. Todavia, nada impede que o poder geral de efetividade da jurisdição possa adaptá-la em cada situação jurídica concreta a fim de obter o melhor resultado executivo, principalmente considerando o contexto da atipicidade e a valorização pelo direito fundamental à efetividade da tutela satisfativa adequada às obrigações específicas.

Aliás, é justamente em reforço ao cumprimento das obrigações na forma específica que diversas medidas coercitivas, de modalidades distintas, foram autorizadas para atuar sobre a vontade do recalcitrante(GAIO JÚNIOR, 2019, p. 05), razão pela qual a própria astreinte, mesmo típica, deve ser racionalizada, ainda que atipicamente, para o caso concreto.

Não se tem dúvida acerca da intensidade de aplicação da multa coercitiva. Certamente a astreinte é medida executiva aplicada constantemente na prática forense brasileira, até porque a sua fixação não depende de muita fundamentação concreta diante dos indicativos da própria legislação. Se a técnica é típica e constantemente trabalha, seu estabelecimento requer menos esforço.

No entanto, é precisamente sua fixação desprovida de sólidos parâmetros que se deve combater, pois a ausência de balizas tangíveis pode tornar a multa inócua e sem o sentido pela qual ela existe. Portanto, não basta seu estabelecimento repetitivo e sem apreciação casuística, faz-se necessário bem mais, pois sua finalidade é a efetiva satisfação da tutela. É esse o fim precípuo dos meios coercitivos.

O ponto mais óbvio a ser considerado diz respeito ao valor a ser estabelecido acessoriamente. Logicamente o montante possível de ser atingido pela multa somente será adequado se for realmente capaz de viabilizar a efetividade jurisdicional, paralelamente entre a quantia suficiente para atingir a coerção e de modo que o obrigado possua reais condições patrimoniais para arcar com as consequências. Fora dessas situações, a multa não terá qualquer 
efetividade. (MARINONI, 2020, p. 15)

É preciso observar que a execução visa à tutela jurisdicional stricto sensu, sendo esta o fim almejado pela imposiçãoda multa, razão pela qual ela não tem fim em si mesma, mas consiste apenas em meio enquanto manifestação do império jurisdicional (AMARAL, 2010, p. 69 e 70). Essa relação precisa ficar bem destacada para que se tenha exata noção do que a multa deve resguardar quando do seu estabelecimento.

Considerando que apenas o caso concreto irá oferecer as condições de análise para o estabelecimento adequado da medida, deve-se observar "o objeto da tutela e a eficácia coercitiva esperada da medida, levando-se em conta os princípios da razoabilidade e proporcionalidade" (WAMBIER, 2012, p. 15 e 16), de modo que o parâmetro a ser seguido "é o da suficiência e compatibilidade da obrigação de fazer a ser cumprida pela parte, de sorte que a multa pecuniária seja apta a tornar efetivo o seu intuito inibitório.” (PEREIRA, 2018, p. 110)

Portanto, a estimativa de valor deverá levar em consideração o próprio bem jurídico tutelado materialmente. Muitas vezes isso requer atividade de alta complexidade, pois há bens, a exemplo da vida ou da liberdade, que não possuem valor factível. A despeito disso, dever-se-á tomar em consideração o poder patrimonial de quem deverá cumprir a medida, a fim de averiguar a capacidade de coerção, inadmitir o enriquecimento ilícito do exequente, e, por fim e não menos importante, apontar se a multa coercitiva consiste, de fato, na melhor solução ao caso concreto. Por mais que seja pomposa, não significa que essa medida deva sempre ser aplicada.

Ponto que também merece destaque diz respeito à periodicidade da multa, sendo permitido ao juiz estabelecê-la conforme as situações concretas. Mais uma vez irá se exigir criatividade jurisdicional, adequando o caso apresentado com a fixação da astreinte. Exemplo interessante foi apresentado por Olavo de Oliveira Neto (2019, p. 246), no qual haveria obrigação de uma fábrica a instalar filtros antipoluição no prazo de dez dias, sob pena de paralisação paulatina das atividades de produção por cinco minutos a cada dia de atraso.

Observe-se que o exemplo acima não envolve a multa, mas a criatividade exigida através da liberdade do aplicador. Imagine-se, agora, a ordem destinada a determinado estabelecimento para a construção de banheiros com acessibilidade, rampa para cadeirantes e corrimão. Em razão da diferença temporal exigida entre cada obra, nada impede que a astreinte para a construção do corrimão incida diariamente, ao tempo em que para o banheiro e rampa semanalmente. A racionalidade deverá sempre ser concreta, criativa e factível.

Outro aspecto relevantíssimo diz respeito a quem deverá ser direcionada a multa coercitiva, isto porque a legislação processual dispõe que incumbirá ao executado. Ocorre que não parece existir óbice para seu redirecionamento através do poder geral de efetivação jurisdicional. É o caso já admitido, por exemplo, da fixação da astreinte ao gestor nas demandas em face do Poder Público (CUNHA, 2018), ou até mesmoquanto aosadministradores das pessoas jurídicas de direito privado (ZARONI, 2007), desmistificando a ideia de que atos executivos não 
possam alcançar terceiros e que isso afeta eventuais limites subjetivos da coisa julgada.

Também é possível, através da flexibilização processual e da execução negociada, que o disposto no art. $537, \S 2^{\circ}$, do CPC/15, seja re lativizado, destinando o valor da multa para outro que não seja o exequente. Tal medida poderia, circunstancialmente, reforçar o obrigado pela ordem a cumprir com o determinado.

Especificamente sobre a execução negociada, entende-se categoricamente que a disponibilidade executória permite a adequação casuística fundada no interesse dos envolvidos, abrindo-se amplo espaço à negociação processual quanto às medidas executivas (NOGUEIRA, 2018, p. 04). Sendo assim, a vontade dos interessados é crucial para a eficiência dos atos executivos, sendo necessária sua valorização, incentivo e criatividade, através de uma sistemática cooperativa e disponível.

Enfim, nota-se o que Eduardo Talamini (2000, p. 02) já alertava no início do século, quando afirmava que a possibilidade do emprego de mecanismo geral funcionava como norma de encerramento do sistema, assegurando que as situações carentes de proteção ficassem efetivamente protegidas, e não apenas as previstas pelo legislador.

No caso da multa coercitiva, mesmo sendo típica, percebe-se claramente que sua adequação ao caso concreto merece ser pormenorizada, a fim de lograr êxito na sua finalidade acessória, que é servir de instrumento hábil para tornar a atividade satisfativa realmente efetiva. Esse propósito encontra total amparo em um sistema normativorespaldado pelaforça dos direitos fundamentais e da atipicidade executória.

\section{CONCLUSÃO}

Observou-se que a tutela específica no novo Código de Processo Civil deu continuidade ao que já estava disposto na legislação anterior, conquista legal obtida somente no final do século passado. Mas mais que isso, a valorização promovida pelo CPC/15 sobre a execução reforça, em caráter sistemático, o desenvolvimento de técnicas executivas suficientes à satisfação.

Assim, o direito fundamental à efetividade da tutela satisfativa ganhou realce considerável, principalmente se considerada a passagem importante de um modelo rígido para os permissivos atípicos da execuçãocivil. Na perspectiva dessaflexibilização, encontram-se também as multas coercitivas.

As astreintes, como visto, consistem em técnica coercitiva de execução indireta, no intuito de constranger alguém pela ameaça em pecúnia a cumprir com a respectiva conduta esperada. Porém, mesmo sua previsão legal implica na necessidade de racionalização para que a medida obtenha resultados práticos e positivos.

Portanto, os aspectos da multa devem ser apreciados casuisticamente para que sua aplicação tenha sentido concreto, tais quais o valor, a periodicidade, a destinação da multa ou a destinação do crédito. Procedendo-se dessa maneira, a probabilidade de sucesso da técnica 
executiva aumenta consideravelmente, honrando a seriedade da medida.

\section{REFERÊNCIAS}

AMARAL, Guilherme Rizzo. As astreintes e o processo civil brasileiro: multa do artigo 461 do CPC e outras. 2. ed. rev. atual. e ampl. Porto Alegre: Livraria do Advogado Editora, 2010.

AMARAL, Guilherme Rizzo. Do cumprimento de sentença que reconheça a exigibilidade de obrigação de fazer, de não fazer ou de entregar coisa. In WAMBIER et al. (Coord.). Breves comentários ao novo Código de Processo Civil. São Paulo: Editora Revista dos Tribunais, 2015.

ATAÍDE JÚNIOR, Vicente de Paula. A multa coercitiva como crédito do Estado. Dissertação de mestrado. Pós-graduação em Direito na Universidade Federal do Paraná. Curitiba, 2008.

BORGES, Marcus Vinícius Motter. Medidas coercitivas atípicas nas execuções pecuniárias: parâmetros para a aplicação do art. 139, IV do CPC/15. São Paulo: Thomson Reuters, 2019.

CHABAS, François. L'astreinte em droit français. Doutrinas essenciais Obrigações e Contratos, v. 2, p. 1159-1164, jun. 2011.

CUNHA, Leonardo Carneiro da. A Fazenda Pública em Juízo. 15. ed. rev. atual. e ampl. Produção digital. Rio de Janeiro: Forense, 2018.

CUNHA, Guilherme Cardoso Antunes; SCALABRIN, Felipe. A menor onerosidade na perspectiva do direito fundamental à tutela executiva. Revista de Processo, n. 271, p. 179-228, set. 2017.

DIDIER JÚNIOR, Fredie. Esboço de uma teoria da execução civil. Revista de Processo, n. 118, p. 9-28, nov/dez. 2004.

DURO, Cristiano. Execução e democracia. Salvador: Juspodivum, 2018.

FONSECA E SILVA, Augusto Vinícius. Princípios pamprocessuais ou metaprocessuais. Salvador: Editora Juspodivm, 2018.

GAIO JÚNIOR, Antônio Pereira. Medidas de execução indireta (típicas e atípicas) e a busca pela satisfação efetiva do direito. Revista de Processo, n. 294, p. 169-194, ago. 2019.

GEBRIM, Marilza Neves. Astreintes. Revista da Escola Superior da Magistratura do Distrito Federal. Brasília, v.3. n.6, dez., p.107-123, 1996.

GRINOVER, Ada Pellegrini. Tutela jurisdicional nas obrigações de fazer e não fazer. Doutrinas Essenciais de Processo Civil, n. 2, p. 187-203, out. 2011.

MARINONI, Luiz Guilherme. Técnica processual e tutela dos direitos. 6. ed. rev. e atual. São Paulo: Thomson Reuters Brasil, 2019.

MARINONI, Luiz Guilherme. Tutela ressarcitória na forma específica. Revista de Processo, n. 300, fev., p.34-51, 2020.

MARZAGÃO, Newton Coca Bastos. A multa (astreintes) na tutela específica. Dissertação de mestrado. Faculdade de Direito, Universidade de São Paulo. São Paulo, 2013.

MEDINA, José Miguel Garcia. Execução: Teoria Geral, princípios fundamentais e procedimento no processo civil brasileiro. 5. ed. rev., ampl. e atual. São Paulo: Editora Revista dos Tribunais, 2017.

MINAMI, Marcos Youji. Da vedação ao non factibile: uma justificativa às medidas executivas atípicas. Revista de Processo, n. 288, p. 181-208, fev. 2019.

NETTO, José Manoel de Arruda Alvim. Obrigações de fazer e não fazer - direito material e processo. Revista de Processo, n. 99, p. 27-39, ju1/set. 2000.

NOGUEIRA, Pedro Henrique Pedrosa. Gestão da execução por meio de negócios jurídicos 
processuais no processo civil brasileiro. Revista de Processo, n. 286, p. 325-342, dez. 2018.

NOGUEIRA, Pedro Henrique Pedrosa. O direito fundamental à tutela jurisdicional executiva e a técnica da ponderação. Doutrinas Essenciais de Direitos Humanos, v. 1, p. 869-889, ago. 2011.

OLIVEIRA NETO. Olavo. O poder geral de coerção. São Paulo: Thomson Reuters, 2019.

PEREIRA, Rafael Caselli. A multa judicial (astreinte) e o CPC/2015. 2. ed. rev. e ampl. Porto Alegre: Editora Livraria do Advogado, 2018.

RAMOS, Newton. Poderesdo juiz no processocivil e sua conformaçãoconstitucional. Editora Juspodivm, 2019.

REDONDO, Bruno Garcia. Astreintes: aspectos polêmicos. Revista de Processo. São Paulo: Revista dos Tribunais, n. 38, n. 222, p. 65-89, ago. 2013.

RODRIGUES, Victor Martins Ramos. A execução das obrigações de fazer e de não fazer contra o Estado fundada em título judicial (1973-2006). Dissertação de mestrado. Faculdade de Direito de Campos, Centro Universitário Fluminense. Campo dos Goytacazes, 2006.

TALAMINI, Eduardo. As tutelas típicas relativas a deveres de fazer e de não fazer e a via geral do art. 461 do CPC. Revista de Processo, n. 97, p. 173-181, jan/mar. 2000.

TALAMINI, Eduardo. Poder geral de adoção de medidas coercitivas e sub-rogatórias nas diferentes espécies de execução. Revista de Processo, n. 284, p. 139-184, out. 2018.

THEODORO JÚNIOR, Humberto. Tutela específica das obrigações de fazer e não fazer. Revista de Processo, n. 105, p. 9-33, jan/mar. 2002.

VENOSA, Sílvio de Salvo. Direito civil: obrigações e responsabilidade civil. 17. ed. São Paulo: Atlas, 2017.

WAMBIER, Teresa Arruda Alvim. Execução de astreintes. Pareceres, São Paulo: Revista dos Tribunais, v.13, n. 2, p. 603-672, out. 2012.

ZARONI, Bruno Marzullo. Efetividade da execução por meio da multa: a problemática em relação à pessoa jurídica. Dissertação de mestrado, Setor de Ciências Jurídicas. Universidade Federal do Paraná: Curitiba, 2007.

Artigo recebido em: 2020-04-29

Artigo reapresentado em: 2020-06-29

Artigo aceito em: 2020-07-23 